\title{
The endotoxin-induced increase of cytokines is followed by an increase of cortisol relative to dehydroepiandrosterone (DHEA) in healthy male subjects
}

\author{
R H Straub, A Schuld ${ }^{1}$, J Mullington ${ }^{1}$, M Haack ${ }^{1}$, J Schölmerich \\ and T Pollmächer ${ }^{1}$ \\ Laboratory of Neuroendocrinoimmunology, Department of Internal Medicine I, University Hospital Regensburg, 93042 Regensburg, Germany \\ ${ }^{1}$ Max-Planck-Institute of Psychiatry, 80804 München, Germany \\ (Requests for offprints should be addressed to R H Straub; Email: rainer.straub@klinik.uni-regensburg.de)
}

\begin{abstract}
Dehydroepiandrosterone (DHEA) and DHEA sulphate (DHEAS) inhibit T-helper lymphocyte type 2 immune reactions and exert anti-inflammatory effects in some chronic inflammatory diseases. Both DHEA and, in particular, DHEAS levels are dramatically decreased in chronic inflammatory diseases whereas cortisol levels remain stable or are elevated. However, the time course of cortisol relative to DHEA production is not known. We tested whether administration of endotoxin to healthy male subjects can induce an early predominance of cortisol relative to DHEA and DHEAS. It is demonstrated that endotoxin induces a dose-dependent increase of cortisol in relation to DHEA (no effect at $0 \cdot 2 \mathrm{ng}$ endotoxin $/ \mathrm{kg}$ body weight (b.w.), clear effect at 0.4 and $0.8 \mathrm{ng} / \mathrm{kg}$ b.w., $P<0.05$ ) and DHEAS (tested at $0.4 \mathrm{ng} / \mathrm{kg}$ b.w., $P=0 \cdot 014)$. The increase of cortisol relative to DHEA
\end{abstract}

appears $4 \mathrm{~h}$ after endotoxin injection and $2 \mathrm{~h}$ after a strong increase of interleukin (IL)-6 relative to tumour necrosis factor (TNF). In addition, an increase of cortisol relative to $17 \mathrm{OH}$-progesterone was observed. The ratio of serum IL-6/TNF was positively correlated with the ratio of serum cortisol/DHEA $\left(R_{\text {Rank }}=0 \cdot 472, P=0 \cdot 041\right)$ and serum cortisol $/ 17 \mathrm{OH}$-progesterone $\left(R_{\mathrm{Rank}}=0.514\right.$, $P=0.048)$. In conclusion, dissociation of cortisol relative to DHEA, DHEAS or $17 \mathrm{OH}$-progesterone appears very early during a systemic inflammatory response which is associated with an increase of IL-6 relative to TNF. As in chronic inflammatory diseases, during an acute inflammatory response with endotoxin, these physiological hormone changes are probably necessary to achieve adequate cortisol levels at the expense of adrenal androgens.

Journal of Endocrinology (2002) 175, 467-474

\section{Introduction}

Dehydroepiandrosterone (DHEA) has been shown to inhibit proinflammatory cytokines such as secretion of tumour necrosis factor (TNF) (Danenberg et al. 1992, Di Santo et al. 1996, Araghi-Niknam et al. 1997, Kimura et al. 1998, Padgett \& Loria 1998) and interleukin (IL)-6 (Daynes et al. 1993, Straub et al. 1998a, Gordon et al. 2001). On the other hand, DHEA seems to favour T-helper lymphocyte type (Th) 1 reactions whereas DHEA inhibits Th2 immune responses (Wilder 1996a). DHEA may exert an anti-inflammatory effect in Th2driven diseases (van Vollenhoven et al. 1995, Andus et al. 2000) and a more proinflammatory effect in Th1-driven diseases. Thus, in some diseases, decreased serum hormone levels of DHEA and DHEA sulphate (DHEAS) may be unfavourable.

DHEAS is dramatically decreased in most chronic inflammatory diseases but this phenomenon is still unexplained (Masi et al. 1984, Sambrook et al. 1988,
Hedman et al. 1992, Hall et al. 1993, Nilsson et al. 1994, de la Torre et al. 1995, Mateo et al. 1995, Wilder 1996b, Formiga et al. 1997, Straub et al. 1998b, Cutolo et al. 1999). As expected, prior glucocorticoid treatment further decreases DHEAS, which has been demonstrated in several diseases (Sambrook et al. 1988, Hedman et al. 1992, Hall et al. 1993, Straub et al. 1998b). Low levels of DHEAS have also been demonstrated after short-term inflammatory states such as acute cholestasis (Zietz et al. 2001a). Thus, there seems to be an early inflammation-dependent deterioration of androgen production in the adrenal glands.

In this study, we wanted to investigate whether lowdose endotoxinaemia by administration of lipopolysaccharide (LPS) of Salmonella abortus equi in healthy male volunteers leads to an early predominance of cortisol in relation to DHEA or DHEAS. The prominent increase of IL-6 and TNF may be the most important factor for this phenomenon (Michie et al. 1988, Mastorakos et al. 1993, Pollmächer et al. 1993, Späth-Schwalbe et al. 1994, Tilders et al. 1994). Thus, we measured these two important 
cytokines in order to shed light on their possible role for the dissociation of cortisol relative to DHEA, DHEAS or $17 \mathrm{OH}$-progesterone.

\section{Subjects, Materials and Methods}

\section{Experimental subjects}

The experimental procedure was approved by the Ethics Committee for Human Experimentation at the MaxPlanck-Institute of Psychiatry. In the dose-response study, 17 healthy male subjects (mean age 25.8 years; range 21-33 years) and in the single-dose study 24 healthy male subjects (mean age: $27 \cdot 4$ years, range $21-35$ years) participated after having given written informed consent. These healthy men were subjects of earlier studies that investigated different aspects of endotoxin injection (Schuld et al. 2000, Mullington et al. 2000, Haack et al. 2001). All subjects were screened by medical history, physical examination, laboratory investigations, electrocardiogram and electroencephalogram to exclude acute and chronic illness.

\section{Endotoxin preparation}

A standardised sterile preparation of Salmonella abortus equi endotoxin was used which was essentially free of protein and nucleic acids (see Galanos et al. (1979) for details of preparation and properties).

\section{Experimental procedure}

At $1630 \mathrm{~h}$, the subjects entered the laboratory and were under continuous observation during the entire experiment. At $1700 \mathrm{~h}$, an i.v. canula was inserted into an antecubital vein. The blood line was kept patent with saline solution containing heparin. One lead electrocardiogram and temperature were monitored throughout the entire experiment. At $1800 \mathrm{~h}$, subjects received a light meal, and later only mineral water was offered ad libitum. At $2300 \mathrm{~h}$, light was turned off and the subjects were instructed to sleep until they woke up spontaneously in the next morning. They were offered breakfast $30 \mathrm{~min}$ after awakening but remained in bed until $1200 \mathrm{~h}$ the next day. Blood was sampled from $2300 \mathrm{~h}$ every $2 \mathrm{~h}$ until $0900 \mathrm{~h}$ the next morning $(3 \mathrm{ml}$ serum and $3 \mathrm{ml}$ plasma; sum $=18 \mathrm{ml}$ serum and $18 \mathrm{ml}$ plasma) while subjects were sleeping. Sampled blood was stabilised with Na-EDTA $(1 \mathrm{mg} / \mathrm{ml}$ blood) and aprotinine (300 KIU/ml blood), and following immediate centrifugation adequate aliquots were stored at $-20{ }^{\circ} \mathrm{C}$ or $-80{ }^{\circ} \mathrm{C}$. At $2300 \mathrm{~h}, 0.9 \%$ saline as a control vehicle or endotoxin was i.v. injected in a single-blind, placebo-controlled fashion. In the dose-response study $0 \cdot 2$ $(n=7), 0 \cdot 4(n=5)$ and $0 \cdot 8(n=5)$ ng endotoxin per $\mathrm{kg}$ body weight (b.w.) were administered. Due to ethical reasons, these doses induce cytokine maxima that are clearly lower as compared with acute infectious diseases. In the singledose study, only $0.4 \mathrm{ng}$ endotoxin $/ \mathrm{kg} \mathrm{b.w}$. was injected $(n=12$ endotoxin, $n=12$ placebo, cross-over design 14 days later). The groups did not differ in mean age or body mass index.

\section{Laboratory parameters}

We used radioimmunometric assays for the quantitative determination of serum levels of cortisol (Coulter Immunotech, Marseilles, France; detection limit: $10 \mathrm{nmol} / \mathrm{l})$. Serum levels of $17 \mathrm{OH}$-progesterone (IBL, Hamburg, Germany; detection limit: $0.3 \mathrm{nmol} / \mathrm{l}$ ), DHEAS (IBL; detection limit: $130 \mathrm{nmol} / \mathrm{l}$ ), DHEA (Diagnostic Systems Laboratory, Webster, Texas; detection limit: 0.13 nmol/l), IL-6 (high sensitivity Quantikine, R\&D Systems, Minneapolis, MN, USA; detection limit: $0 \cdot 2 \mathrm{pg} / \mathrm{ml}$ ) and TNF (high sensitivity Quantikine, R\&D Systems; detection limit: $0.2 \mathrm{pg} / \mathrm{ml}$ ) were measured by means of immunometric enzyme immunoassays. Intraassay and interassay coefficients of variation were below $10 \%$ in each test.

\section{Statistical analysis}

In order to compare means in two different groups the Mann-Whitney signed rank test was used (SPSS/PC for Windows, V.10.0.5, SPSS, Inc., Chicago, IL, USA). Regression analysis was done by Spearman rank correlation analysis (SPSS) and linear regression lines are demonstrated in the Figures. Time-related changes of serum IL-6 concentration within the control group during the night was detected by the non-parametric Friedman test for numerous dependent values (SPSS). In this Friedman test, $P<0 \cdot 05$ indicates a significant change of the variable during the test procedure, which demonstrates an increase over time. $P$-values of less than 0.05 were considered to be significant and means are always given \pm S.E.M.

\section{Results}

Serum levels of adrenal hormones during the endotoxin test

Four hours after injection of $0.4 \mathrm{ng}$ endotoxin $/ \mathrm{kg}$ b.w., we observed a significant increase of serum levels of cortisol as compared with control conditions (Fig. 1A). During the following time, serum levels of cortisol under control conditions also increased and, thus, no difference was detected between 0500 and 0900 h (Fig. 1A). No marked differences were observed for serum levels of $17 \mathrm{OH}-$ progesterone, DHEA and DHEAS (Fig. 1B,C,D).

\section{Serum levels of cytokines during the $0 \cdot 4 \mathrm{ng} / \mathrm{kg}$ endotoxin test}

As demonstrated in Fig. 2, there was a marked increase of serum TNF and serum IL-6 with a maximum at $2 \mathrm{~h}$ after 

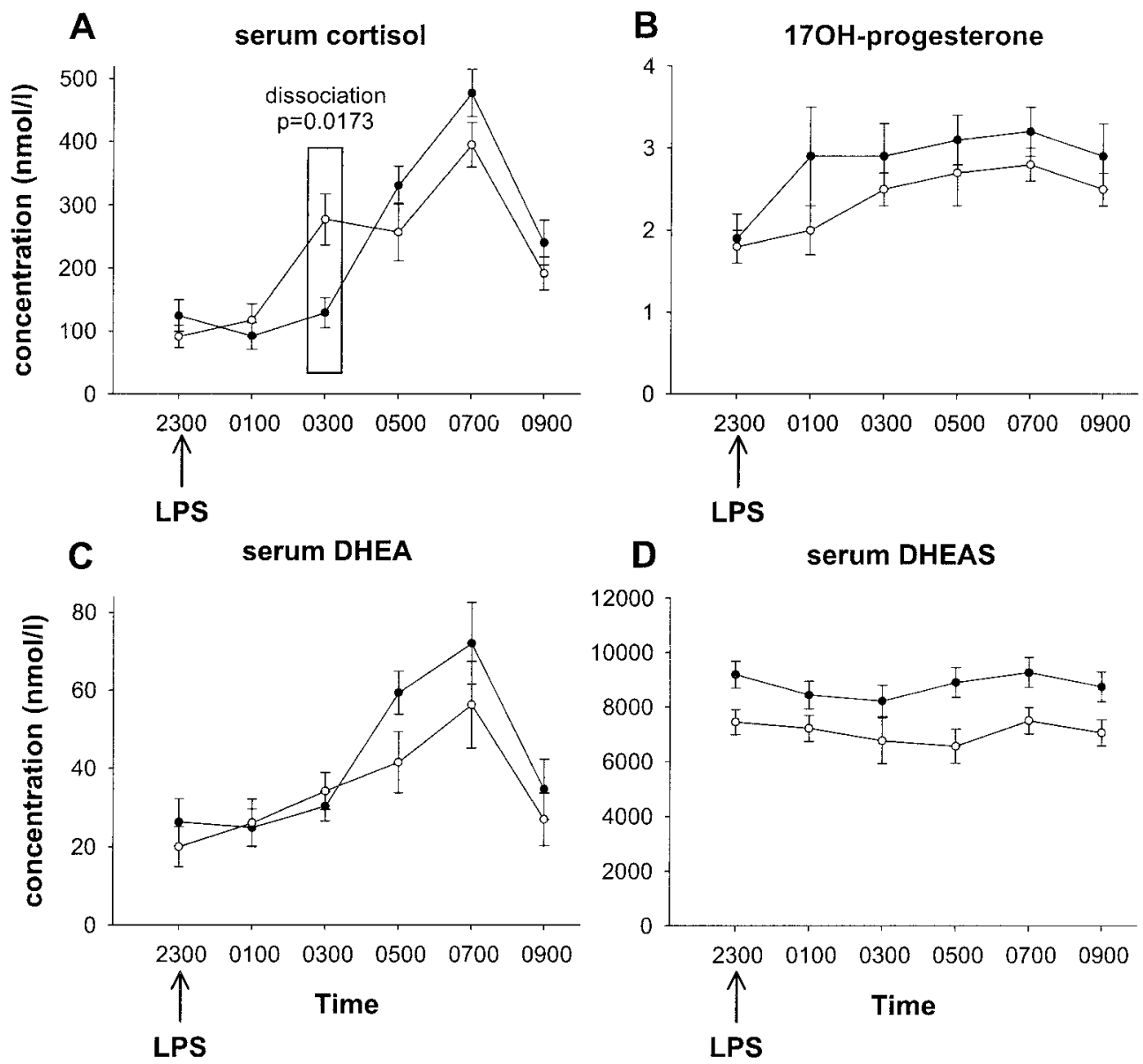

Figure 1 Time course of adrenal steroid hormones after i.v. endotoxin injection in healthy male volunteers. Serum levels of cortisol (A), 17OH-progesterone (B), DHEA (C) and DHEAS (D) are depicted in nmol/l. Filled symbols represent data \pm S.E.M. of subjects under control conditions, and open symbols demonstrate serum levels of subjects after i.v. injection of $0.4 \mathrm{ng}$ endotoxin per $\mathrm{kg}$ b.w. The rectangle in (A) demonstrates the dissociation of the two curves in patients with/without prior endotoxin administration.

endotoxin injection $(0100 \mathrm{~h})$. In addition, under control conditions, subjects demonstrated a small early morning rise of serum IL-6 $(P=0.002$ in the Friedman test, Fig. 2B). Furthermore, control subjects demonstrated elevated levels of TNF in relation to IL-6 $2 \mathrm{~h}$ after endotoxin injection (Fig. 2C), which was the opposite $6 \mathrm{~h}$ after endotoxin injection (Fig. 2C). Thus, under endotoxin conditions, this ratio completely switched from a preponderance of IL-6 at $0100 \mathrm{~h}$ versus a preponderance of TNF between $0500 \mathrm{~h}$ and $0900 \mathrm{~h}$ (Fig. 2C).

\section{Molar ratios of serum levels of adrenal hormones}

At $4 \mathrm{~h}$ after endotoxin injection $(2 \mathrm{~h}$ after cytokine maximum), the molar ratio of serum cortisol/17OHprogesterone and serum cortisol/DHEA was markedly higher in subjects receiving $0.4 \mathrm{ng}$ endotoxin $/ \mathrm{kg}$ b.w. as compared with subjects under control conditions (Fig. 3).
This was very similar for the ratio of serum cortisol/ DHEAS at the same time point (endotoxin vs control: $0 \cdot 252 \pm 0 \cdot 200$ vs $0 \cdot 016 \pm 0 \cdot 003, P=0 \cdot 014)$. During the following time, these ratios were similar in both experimental groups (Fig. 3). In the dose-response study, $4 \mathrm{~h}$ after endotoxin injection, subjects receiving either 0.4 or $0.8 \mathrm{ng}$ endotoxin $/ \mathrm{kg}$ b.w. demonstrated a significantly elevated molar ratio of serum cortisol/serum DHEA (Fig. 4). Furthermore, high serum levels of IL-6 in relation to TNF were correlated with high serum levels of cortisol in relation to DHEA or $17 \mathrm{OH}$-progesterone (Fig. 5).

\section{Discussion}

This study demonstrated an early endotoxin-induced predominance of cortisol in relation to DHEA, DHEAS or $17 \mathrm{OH}$-progesterone $4 \mathrm{~h}$ after LPS injection, which 

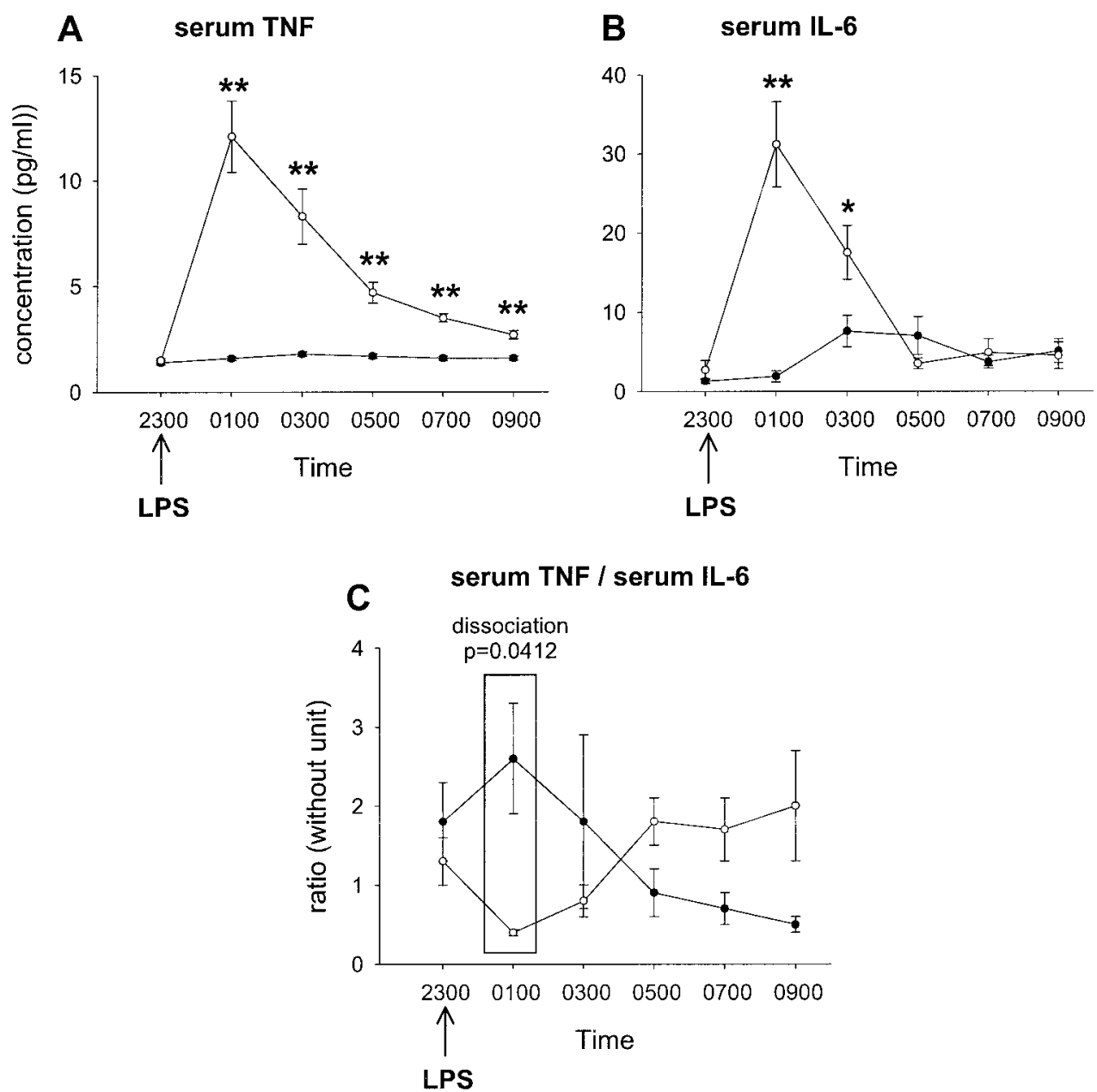

Figure 2 Time course of serum levels of TNF and IL-6 after i.v. endotoxin injection in healthy male volunteers. Serum levels of TNF (A) and IL-6 (B) are depicted in pg/ml. (C) The ratio of serum TNF/serum IL-6. Filled symbols represent data \pm S.E.M. of healthy subjects under control conditions and open symbols demonstrate serum levels of subjects after i.v. injection of $0.4 \mathrm{ng}$ endotoxin per $\mathrm{kg}$ b.w. The rectangle in (C) demonstrates the dissociation of the two curves in patients with/without prior endotoxin administration. ${ }^{*} P<0 \cdot 05,{ }^{*} P<0 \cdot 01$ versus subjects without prior endotoxin administration.

followed a relative increase of serum IL-6 in relation to serum TNF $2 \mathrm{~h}$ after LPS injection. A very similar hormone predominance can be observed in chronic inflammatory disease for serum levels of cortisol relative to DHEAS (Straub et al. 1998b, Zietz et al. 2000) and for serum levels of cortisol relative to DHEA (Straub et al. 1998b). In more acute situations such as early untreated rheumatoid arthritis only an increase of cortisol relative to DHEAS but not relative to DHEA was observed (Straub et al. 2002). Patients with early untreated rheumatoid arthritis have no positive relation between indices of inflammation and cortisol, but serum DHEAS or DHEA levels are inversely correlated with these inflammatory indices (Cutolo et al. 1999, Kanik et al. 2000). In acute reactive arthritis, which is a milder form of an inflamma- tory arthritic disease, no such predominance of cortisol in relation to DHEA, DHEAS or $17 \mathrm{OH}$-progesterone was observed (Straub et al. 2002). In acute cholestasis, a similar predominance of cortisol in relation to DHEAS was observed (DHEA was not measured) (Zietz et al. 2001a). This indicates that adrenal steroid production is changed into the direction of cortisol relative to adrenal androgen such as DHEA and, particularly, DHEAS depending on the degree and duration of inflammation. Similar hormonal predominance is observed in critically ill patients, and it was mentioned that these changes of relative biochemical pathway predominance may be a factor necessary for survival during chronic severe stress (Parker et al. 1985, Drucker \& McLaughlin 1986). However, the reasons for this pathway predominance are still 
Cortisol / 17OH-progesterone

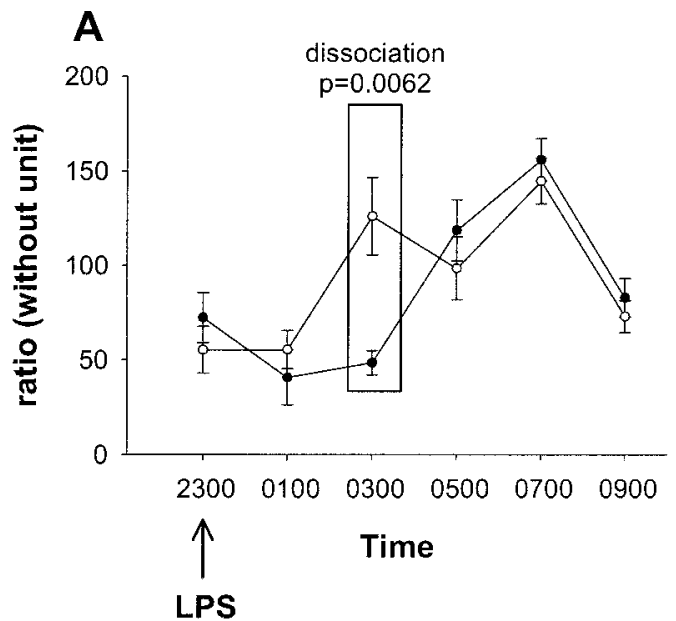

Cortisol / DHEA

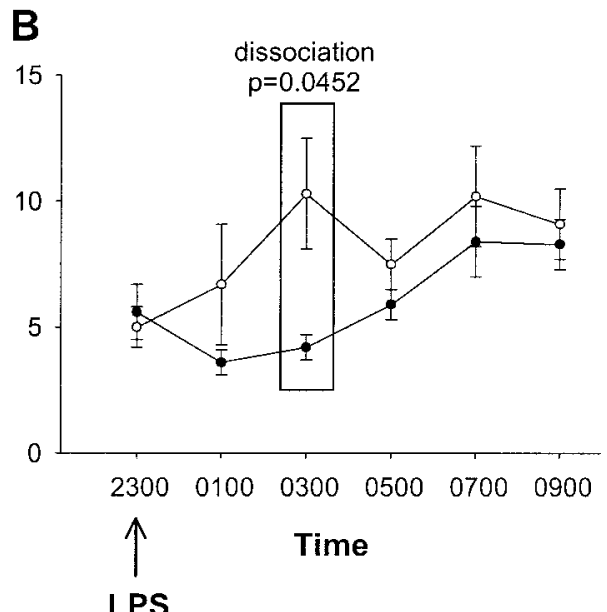

Figure 3 Time course of hormonal ratios after i.v. endotoxin injection in healthy male volunteers. The ratio of serum cortisol/serum $17 \mathrm{OH}$-progesterone $(\mathrm{A})$, and the ratio of serum cortisol/serum DHEA (B) are depicted. Filled symbols represent data \pm S.E.M. of healthy subjects under control conditions and open symbols demonstrate serum levels of subjects after i.v. injection of $0.4 \mathrm{ng}$ endotoxin per $\mathrm{kg}$ b.w. The rectangles demonstrate the dissociation of the two curves in patients with/without prior endotoxin administration.

unknown because no adequate methods are yet available to investigate directly human adult adrenocortical cells of these patients in vivo or in vitro. Thus, only indirect methods can be applied in order to shed light on this obscure phenomenon.

Some key mediators of increased serum levels of cortisol relative to DHEA, DHEAS or $17 \mathrm{OH}$-progesterone may be (a) circulating cytokines such as TNF and IL-6, which exert their specific effects at the level of the adrenocortical cell (Jäättelä et al. 1991, Päth et al. 1996, Barney et al.

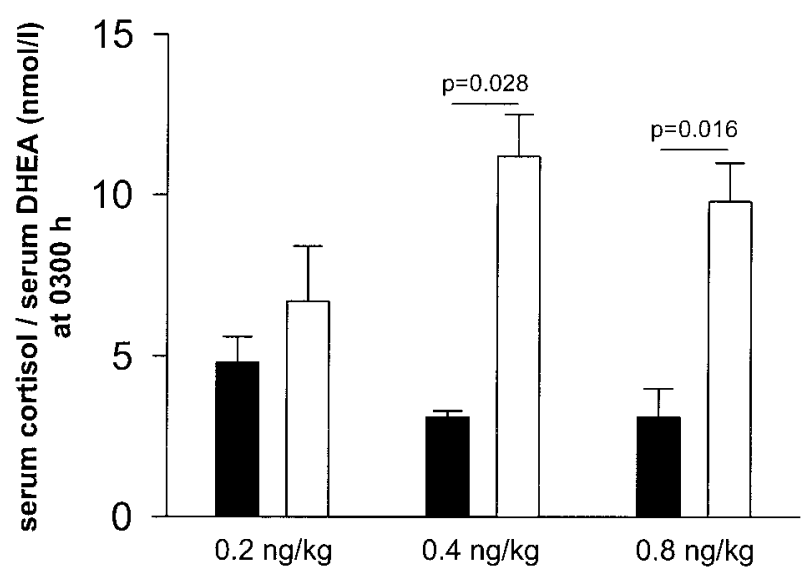

Figure 4 Endotoxin dose-response for the ratio of serum levels of cortisol/DHEA at the time point $0300 \mathrm{~h}$. Underneath the bars, the different injected doses are indicated in ng endotoxin $/ \mathrm{kg}$ b.w. Filled (open) bars represent means \pm S.E.M. of subjects without (with) prior endotoxin injection.
2000), (b) local immune cells in the adrenal gland, which produce cytokines or act via surface molecules (Wolkersdorfer et al. 1999), and (c) neurotransmitters or neuropeptides of innervating nerves of the adrenal glands, whose release may be under control of local cytokines (Ehrhart-Bornstein et al. 1998). Since TNF can inhibit the secretion of cortisol from adrenal cells due to an inhibition of the P450c21 or other factors (Jäättelä et al. 1991, Barney et al. 2000), and IL-6 increases cortisol secretion (Päth et al. 1996, Barney et al. 2000), these cytokines may be relevant for early increased secretion of cortisol relative to DHEA, DHEAS or $17 \mathrm{OH}$-progesterone during endotoxinaemia or chronic inflammatory diseases. In our patients with endotoxinaemia, this effect of TNF and IL-6 may be confirmed by the correlation of the ratio of serum IL-6/ TNF and the ratio of serum cortisol/DHEA (DHEAS, or $17 \mathrm{OH}$-progesterone). This indicates that elevated levels of IL-6 in relation to TNF are associated with elevated cortisol relative to DHEA, DHEAS or $17 \mathrm{OH}-$ progesterone. A very similar finding has been described recently for serum cortisol relative to serum $17 \mathrm{OH}-$ progesterone in early untreated patients with rheumatoid arthritis (Straub et al. 2002). Although this is only indirect evidence from a deductive stand-point, the mentioned inductive experiments with fetal human or bovine adrenocortical cells may confirm this view.

Interestingly, with ageing, a very similar pathway predominance appears, with elevated serum levels of cortisol relative to DHEA or DHEAS (Belanger et al. 1994, Ferrari et al. 2001). During ageing, a similar increase of IL-6 appears which is not paralleled by a similarly intense 


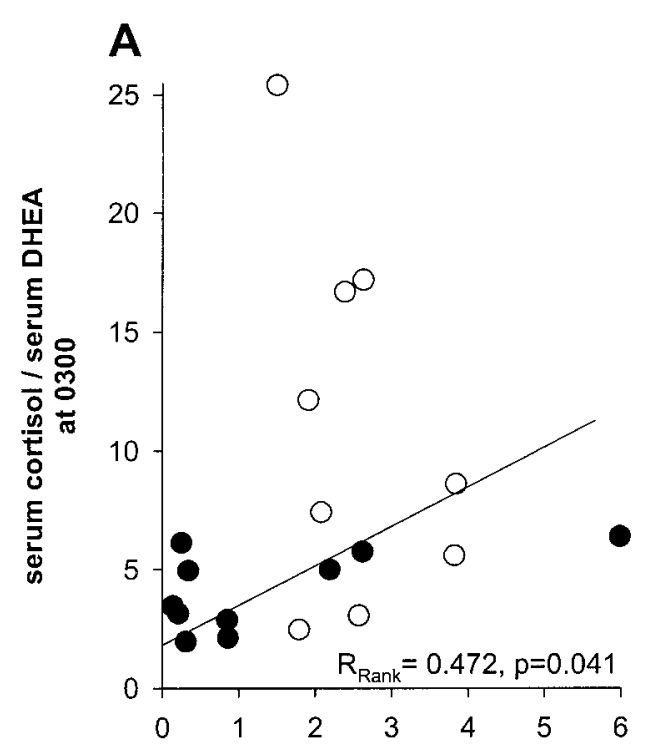

serum IL-6 / serum TNF at 0100

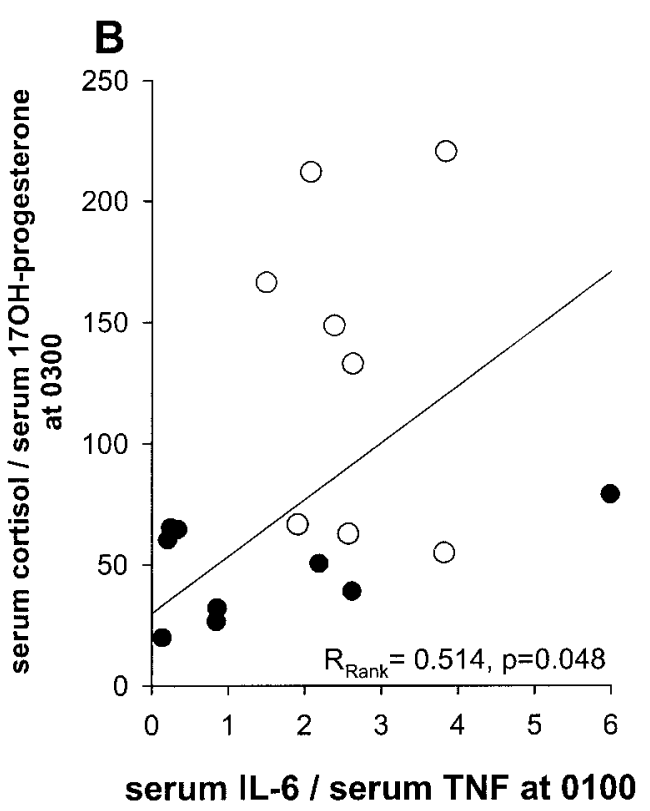

serum IL-6 / serum TNF at 0100

Figure 5 Correlation between cytokine ratio and hormone ratio at the time point $0300 \mathrm{~h}$. (A) The interrelation between the ratio of serum IL-6/TNF and the ratio of serum cortisol/DHEA. (B) The correlation between the ratio of serum IL-6/TNF and the ratio of serum cortisol/17OH-progesterone. The linear regression line, the Spearman rank correlation coefficient $\left(R_{\text {Rank }}\right)$ and its $P$-value are given. Filled (open) symbols represent subjects without (with) prior endotoxin administration.

increase of TNF (Straub et al. 1998a, Zietz et al. 2001b). In this situation, one may speculate that very similar effects modulate adrenal cortisol and androgen production and, possibly, locally or systemically produced cytokines are the main players of these hormonal changes. During ageing, increased adipose tissue may be a relevant source of elevated serum levels of IL-6 but not of TNF (MohamedAli et al. 1997, Fried et al. 1998).

In conclusion, dissociation of cortisol relative to DHEA, DHEAS or $17 \mathrm{OH}$-progesterone appears very early during a systemic inflammatory response which followed an increase of IL-6 relative to TNF. This would suggest a very different role for IL-6 compared with TNF, where IL-6 stimulates and TNF inhibits adrenal steroidogenesis (particularly adrenal androgens). These hormonal changes during an inflammatory response are probably necessary to achieve adequate cortisol levels at the expense of adrenal androgens. Such a relative increase of cortisol is necessary in order to overcome acute severe illness which has been demonstrated in sepsis experiments (Hinshaw et al. 1985). However, in chronic inflammatory diseases, maintenance of this pathway predominance and a generally lower production of adrenal steroids may be deleterious. In these diseases, together with glucocorticoids, DHEA may be a relevant anti-inflammatory agent.

\section{Acknowledgement}

This study was supported by the Deutsche Forschungsgemeinschaft (Str 511/9-1,2,3).

\section{References}

Andus T, Klebl F, Rogler G, Schölmerich J \& Straub RH 2000 Successful treatment of refractory ulcerative colitis with dehydroepiandrosterone (DHEA) - an open controlled pilot trial [Abstract]. Gastroenterology 188 A116.

Araghi-Niknam M, Zhang Z, Jiang S, Call O, Eskelson CD \& Watson RR 1997 Cytokine dysregulation and increased oxidation is prevented by dehydroepiandrosterone in mice infected with murine leukemia retrovirus. Proceedings of the Society of Experimental Biology and Medicine 216 386-391.

Barney M, Call GB, McIlmoil CJ, Husein OF, Adams A, Balls AG, Oliveira GK, Miner EC, Richards TA, Crawford BK, Heckmann RA, Bell JD \& Judd AM 2000 Stimulation by interleukin-6 and inhibition by tumor necrosis factor of cortisol release from bovine adrenal zona fasciculata cells through their receptors. Endocrine $\mathbf{1 3}$ 369-377.

Belanger A, Candas B, Dupont A, Cusan L, Diamond P, Gomez JL \& Labrie F 1994 Changes in serum concentrations of conjugated and unconjugated steroids in 40- to 80-year-old men. Journal of Clinical Endocrinology and Metabolism 79 1086-1090.

Cutolo M, Foppiani L, Prete C, Ballarino P, Sulli A, Villaggio B, Seriolo B, Giusti M \& Accardo S 1999 Hypothalamicpituitary-adrenocortical axis function in premenopausal women with rheumatoid arthritis not treated with glucocorticoids. Journal of Rheumatology 26 282-288.

Danenberg HD, Alpert G, Lustig S \& Ben-Nathan D 1992 Dehydroepiandrosterone protects mice from endotoxin toxicity and reduces tumor necrosis factor production. Antimicrobial Agents and Chemotherapy 36 2275-2279.

Daynes RA, Araneo BA, Ershler WB, Maloney C, Li GZ \& Ryu SY 1993 Altered regulation of IL-6 production with normal aging. Possible linkage to the age-associated decline in dehydroepiandrosterone and its sulfated derivative. Journal of Immunology $\mathbf{1 5 0}$ 5219-5230. 
Di Santo E, Foddi MC, Ricciardi-Castagnoli P, Mennini T \& Ghezzi P 1996 DHEAS inhibits TNF production in monocytes, astrocytes and microglial cells. Neuroimmunomodulation 3 285-288.

Drucker D \& McLaughlin J 1986 Adrenocortical dysfunction in acute medical illness. Critical Care Medicine 14 789-791.

Ehrhart-Bornstein M, Hinson JP, Bornstein SR, Scherbaum WA \& Vinson GP 1998 Intraadrenal interactions in the regulation of adrenocortical steroidogenesis. Endocrine Reviews 19 101-143.

Ferrari E, Cravello L, Muzzoni B, Casarotti D, Paltro M, Solerte SB, Fioravanti M, Cuzzoni G, Pontiggia B \& Magri F 2001 Age-related changes of the hypothalamic-pituitary-adrenal axis:

pathophysiological correlates. European Journal of Endocrinology 144 319-329.

Formiga F, Moga I, Nolla JM, Navarro MA, Bonnin R \& Roig-Escofet D 1997 The association of dehydroepiandrosterone sulphate levels with bone mineral density in systemic lupus erythematosus. Clinical and Experimental Rheumatology 15 387-392.

Fried SK, Bunkin DA \& Greenberg AS 1998 Omental and subcutaneous adipose tissues of obese subjects release interleukin-6: depot difference and regulation by glucocorticoid. Journal of Clinical Endocrinology and Metabolism 83 847-850.

Galanos C, Luderitz O \& Westphal O 1979 Preparation and properties of a standardized lipopolysaccharide from Salmonella abortus equi (Novo-Pyrexal). Zentralblatt für Bakteriooglie 243 226-244.

Gordon CM, LeBoff MS \& Glowacki J 2001 Adrenal and gonadal steroids inhibit IL-6 secretion by human marrow cells. Cytokine $\mathbf{1 6}$ 178-186.

Haack M, Schuld A, Kraus T \& Pollmacher T 2001 Effects of sleep on endotoxin-induced host responses in healthy men. Psychosomatic Medicine 63 568-578.

Hall GM, Perry LA \& Spector TD 1993 Depressed levels of dehydroepiandrosterone sulphate in postmenopausal women with rheumatoid arthritis but no relation with axial bone density. Annals of Rheumatic Diseases 52 211-214.

Hedman M, Nilsson E \& de la Torre B 1992 Low blood and synovial fluid levels of sulpho-conjugated steroids in rheumatoid arthritis. Clinical and Experimental Rheumatology 10 25-30.

Hinshaw LB, Beller BK, Chang AC, Murray CK, Flournoy DJ, Passey RB \& Archer LT 1985 Corticosteroid/antibiotic treatment of adrenalectomized dogs challenged with lethal E. coli. Circulatory Shock 16 265-277.

Jäättelä M, Ilvesmaki V, Voutilainen R, Stenman UH \& Saksela E 1991 Tumor necrosis factor as a potent inhibitor of adrenocorticotropin-induced cortisol production and steroidogenic P450 enzyme gene expression in cultured human fetal adrenal cells. Endocrinology 128 623-629.

Kanik KS, Chrousos GP, Schumacher HR, Crane ML, Yarboro CH \& Wilder RL 2000 Adrenocorticotropin, glucocorticoid, and androgen secretion in patients with new onset synovitis/rheumatoid arthritis: relations with indices of inflammation. Journal of Clinical Endocrinology and Metabolism 85 1461-1466.

Kimura M, Tanaka S, Yamada Y, Kiuchi Y, Yamakawa T \& Sekihara H 1998 Dehydroepiandrosterone decreases serum tumor necrosis factor-alpha and restores insulin sensitivity: independent effect from secondary weight reduction in genetically obese Zucker fatty rats. Endocrinology 139 3249-3253.

Masi AT, Josipovic DB \& Jefferson WE 1984 Low adrenal androgenic-anabolic steroids in women with rheumatoid arthritis (RA): gas-liquid chromatographic studies of RA patients and matched normal control women indicating decreased 11-deoxy-17-ketosteroid excretion. Seminars in Arthritis and Rheumatism 14 1-23.

Mastorakos G, Chrousos GP \& Weber JS 1993 Recombinant interleukin-6 activates the hypothalamic-pituitary-adrenal axis in humans. Journal of Clinical Endocrinology and Metabolism 77 1690-1694.
Mateo L, Nolla JM, Bonnin MR, Navarro MA \& Roig-Escofet D 1995 Sex hormone status and bone mineral density in men with rheumatoid arthritis. Journal of Rheumatology 22 1455-1460.

Michie HR, Manogue KR, Spriggs DR, Revhaug A, O’Dwyer S, Dinarello CA, Cerami A, Wolff SM \& Wilmore DW 1988 Detection of circulating tumor necrosis factor after endotoxin administration. New England Journal of Medicine 318 1481-1486.

Mohamed-Ali V, Goodrick S, Rawesh A, Katz DR, Miles JM, Yudkin JS, Klein S \& Coppack SW 1997 Subcutaneous adipose tissue releases interleukin-6, but not tumor necrosis factor-alpha, in vivo. Journal of Clinical Endocrinology and Metabolism $\mathbf{8 2}$ 4196-4200.

Mullington J, Korth C, Hermann DM, Orth A, Galanos C, Holsboer F \& Pollmacher T 2000 Dose-dependent effects of endotoxin on human sleep. American Journal of Physiology 278 R947-R955.

Nilsson E, de la Torre B, Hedman M, Goobar J \& Thorner A 1994 Blood dehydroepiandrosterone sulphate (DHEAS) levels in polymyalgia rheumatica/giant cell arteritis and primary fibromyalgia. Clinical and Experimental Rheumatology 12 415-417.

Padgett DA \& Loria RM 1998 Endocrine regulation of murine macrophage function: effects of dehydroepiandrosterone, androstenediol, and androstenetriol. Journal of Neuroimmunology 84 61-68.

Parker LN, Levin ER \& Lifrak ET 1985 Evidence for adrenocortical adaptation to severe illness. Journal of Clinical Endocrinology and Metabolism 60 947-952.

Päth G, Bornstein SR, Späth-Schwalbe E \& Scherbaum WA 1996 Direct effects of interleukin-6 on human adrenal cells. Endocrine Research 22 867-873.

Pollmächer T, Schreiber W, Gudewill S, Vedder H, Fassbender K, Wiedemann K, Trachsel L, Galanos C \& Holsboer F 1993 Influence of endotoxin on nocturnal sleep in humans. American Journal of Physiology 264 R1077-R1083.

Sambrook PN, Eisman JA, Champion GD \& Pocock NA 1988 Sex hormone status and osteoporosis in postmenopausal women with rheumatoid arthritis. Arthritis and Rheumatism 31 973-978.

Schuld A, Mullington J, Friess E, Hermann DM, Galanos C, Holsboer F \& Pollmacher T 2000 Changes in dehydroepiandrosterone (DHEA) and DHEA-sulfate plasma levels during experimental endotoxinemia in healthy volunteers. Journal of Clinical Endocrinology and Metabolism 85 4624-4629.

Späth-Schwalbe E, Born J, Schrezenmeier H, Bornstein SR, Stromeyer P, Drechsler S, Fehm HL \& Porzsolt F 1994 Interleukin-6 stimulates the hypothalamus-pituitary-adrenocortical axis in man. Journal of Clinical Endocrinology and Metabolism 79 1212-1214.

Straub RH, Konecna L, Hrach S, Rothe G, Kreutz M, Schölmerich J, Falk W \& Lang B 1998a Serum dehydroepiandrosterone (DHEA) and DHEA sulfate are negatively correlated with serum interleukin-6 (IL-6), and DHEA inhibits IL-6 secretion from mononuclear cells in man in vitro: possible link between endocrinosenescence and immunosenescence. Journal of Clinical Endocrinology and Metabolism 83 2012-2017.

Straub RH, Vogl D, Gross V, Lang B, Schölmerich J \& Andus T $1998 b$ Association of humoral markers of inflammation and dehydroepiandrosterone sulfate or cortisol serum levels in patients with chronic inflammatory bowel disease. American Journal of Gastroenterology 93 2197-2202.

Straub RH, Paimela L, Peltomaa R, Schölmerich J \& Leirisalo-Repo M 2002 Inadequately low serum levels of steroid hormones in relation to IL-6 and TNF in untreated patients with early rheumatoid arthritis and reactive arthritis. Arthritis and Rheumatism 46 654-662.

Tilders FJ, DeRijk RH, Van Dam AM, Vincent VA, Schotanus K \& Persoons JH 1994 Activation of the hypothalamus-pituitary-adrenal axis by bacterial endotoxins: routes and intermediate signals. Psychoneuroendocrinology 19 209-232. 
de la Torre B, Fransson J \& Scheynius A 1995 Blood dehydroepiandrosterone sulphate (DHEAS) levels in pemphigoid/pemphigus and psoriasis. Clinical and Experimental Rheumatology 13 345-348.

van Vollenhoven RF, Engleman EG \& McGuire JL 1995

Dehydroepiandrosterone in systemic lupus erythematosus. Results of a double-blind, placebo-controlled, randomized clinical trial. Arthritis and Rheumatism 38 1826-1831.

Wilder RL 1996a Hormones and autoimmunity: animal models of arthritis. Baillieres Clinical Rheumatology 10 259-271.

Wilder RL 1996b Adrenal and gonadal steroid hormone deficiency in the pathogenesis of rheumatoid arthritis. Journal of Rheumatology (Suppl) 44 10-12.

Wolkersdorfer GW, Lohmann T, Marx C, Schroder S, Pfeiffer R, Stahl HD, Scherbaum WA, Chrousos GP \& Bornstein SR 1999 Lymphocytes stimulate dehydroepiandrosterone production through direct cellular contact with adrenal zona reticularis cells: a novel mechanism of immune-endocrine interaction. Journal of Clinical Endocrinology and Metabolism 84 4220-4227.
Zietz B, Reber T, Oertel M, Glück T, Schölmerich J \& Straub RH 2000 Altered function of the hypothalamic stress axes in patients with moderately active systemic lupus erythematosus. II.

Dissociation between androstenedione, cortisol, or dehydroepiandrosterone and interleukin 6 or tumor necrosis factor. Journal of Rheumatology 27 911-918.

Zietz B, Wengler I, Messmann H, Lock G, Scholmerich J \& Straub RH 2001a Early shifts of adrenal steroid synthesis before and after relief of short-term cholestasis. Journal of Hepatology 35 329-337.

Zietz B, Hrach S, Schölmerich J \& Straub RH $2001 b$ Differential age-related changes of hypothalamus-pituitary-adrenal axis hormones in healthy women and men - role of interleukin 6 . Experimental and Clinical Endocrinology and Diabetes 109 1-9.

Received in final form 2 July 2002

Accepted 31 July 2002 